\title{
COMPUTATIONAL MODELLING OF A FOUR STOREY POST-TENSIONED CONCRETE BUILDING SUBJECTED TO SHAKE TABLE TESTING
}

\author{
Jonathan Watkins ${ }^{1}$, Sri Sritharan ${ }^{2}$, Takuya Nagae $^{3}$ \\ and Richard S. Henry ${ }^{4}$
}

(Submitted April 2017; Reviewed June 2017; Accepted October 2017)

\begin{abstract}
Prior research into low-damage wall systems has predominately focused on the walls behaviour in isolation from other building components. Although the response of these isolated walls has been shown to perform well when subjected to both cyclic and dynamic loading, uncertainty exists when considering the effect of interactions between walls and other structural and non-structural components on the seismic response and performance of entire buildings. To help address this uncertainty a computational model was developed to simulate the response of a full-scale four-storey building with post-tensioned precast concrete walls that was subjected to tri-axial earthquake demands on the E-Defence shake table. The model accurately captured the buildings measured response by incorporating the in-plane and out-of-plane non-linear behaviour of both the wall and floor elements. The model was able to simulate the deformation demands imposed on the floor due to compatibility with the post-tensioned walls, closely matching the behaviour and damage observed during the test. Dynamic loading and wall-to-floor interaction were shown to significantly increase the over-strength actions that developed when compared to the wall system considered in isolation.
\end{abstract}

\section{INTRODUCTION}

Recent earthquakes have confirmed that reinforced concrete (RC) buildings built to modern seismic design standards have generally performed as per the adopted design philosophy by protecting the lives of their occupants. However, the structural damage suffered by conventional RC buildings during major earthquakes can result in the cost of repair being uneconomical, leading to their demolition. For example, $60 \%$ of the multi-storey RC buildings in the Christchurch city centre were demolished following the 2010-2011 Canterbury earthquakes in New Zealand, despite many suffering what was considered to be only moderate structural damage [1]. These findings have increased the demand for development and implementation of low-damage building designs that can be rapidly re-occupied following a major earthquake, thereby limiting the economic consequences for the building owner.

Unbonded post-tensioned precast concrete walls are one alternative to achieve a low-damage seismic resisting system. Since the late 1990's, the results of each experimental investigation into this wall system have reported that the walls exhibit a dependable rocking behaviour with minimal structural damage and residual drifts [2-9]. However, there has been relatively little research conducted on the seismic response of buildings that utilise these wall systems. When subjected to a lateral-load, the behaviour of the wall is characterised by a single horizontal crack opening up at the wall base. This uplift, which is comparable to that expected in cast-in-place wall buildings [5], introduces a relative vertical displacement and rotation at each wall-to-floor interface, as shown in Figure 1. Henry et al. [10] reported that wall-to-floor interaction increased the lateral-load capacity of a prototype building that utilised unbonded post-tensioned precast concrete walls by as much as $50 \%$ at $2 \%$ lateral drift when compared to the prototype building that isolated the floor from the wall uplift. The effects of wall-to-floor interaction can be significant and could result in the building experiencing residual drifts and not achieving its intended low-damage performance criteria due to the time required to repair floor damage. Furthermore, the increased over-strength demands that occur due to wall-to-floor interaction may result in undesirable wall behaviour, such as shear failure or base sliding.

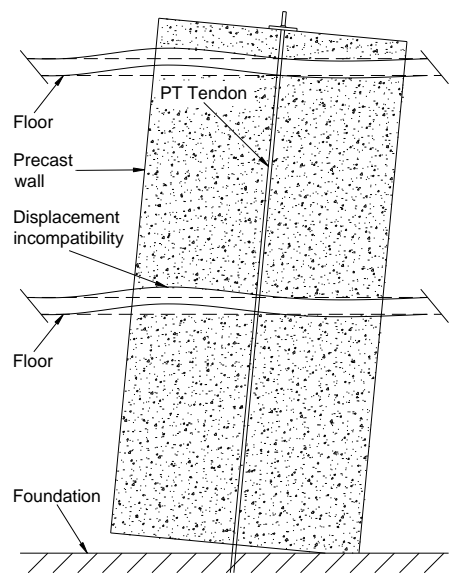

Figure 1: Lateral load behaviour of a rocking wall.

To properly investigate the effects of wall-to-floor interaction large-scale building tests are required. Notable tests of buildings that utilised unbonded post-tensioned precast concrete walls include the PRESSS five storey building [2], the three-storey precast building tested on the UCSD shake table [11], and the four-storey precast post-tensioned building tested on the E-Defence shake table [12]. The PRESSS and UCSD building used specially designed wall-to-floor

\footnotetext{
1 Corresponding Author, Structural Engineer, Beca, Auckland, New Zealand, jonathan.watkins@beca.com

2 Professor, Iowa State University, Iowa, United States of America

3 Associate Professor, Disaster Mitigation Research Center Nagoya University, Chikusa, Nagoya, Aichi, Japan

4 Senior Lecturer, University of Auckland, Auckland, New Zealand (Member)
} 
connectors that isolated the floor from the uplift of the wall to provide more dependable wall behaviour. The E-Defence building used a wall-to-floor detail that is typical of current practice, using precast floors and a cast-in-situ topping with continuity reinforcement. Prior numerical investigations into the response of the E-Defence building did not fully consider the effect that the potential displacement incompatibility between the wall and floor had on the response of the building $[13,14]$. To address the effects of wall-to-floor interaction on the building response, an analytical investigation was undertaken using a 3D numerical model representing the E-Defence test building.

\section{TEST BUILDING}

A brief description of the test building is provided to enable understanding of the computational model and full details of the building and test program were published by the joint Japanese and United States research team $[12,15,16]$. The building was designed to a mixture of Japanese and United States standards and it should be noted that some details such

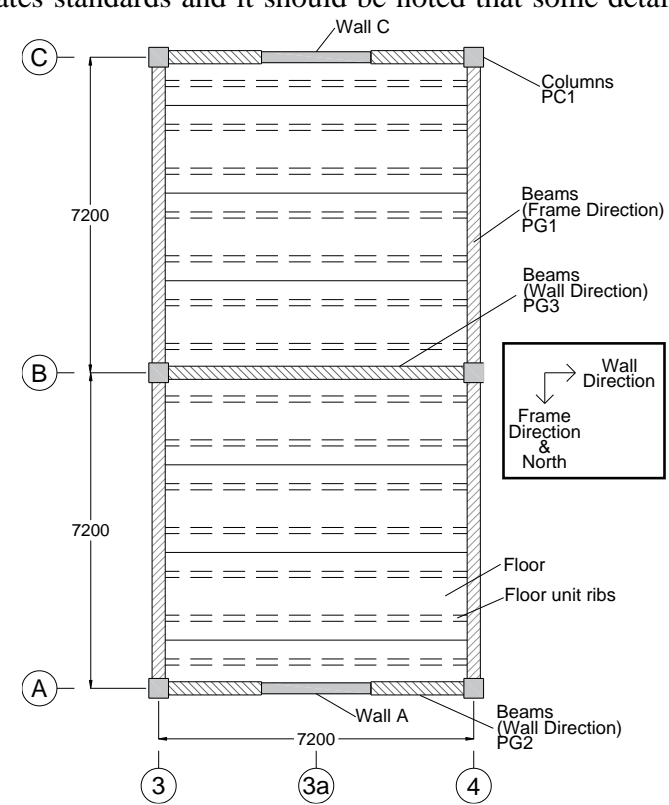

(a) Plan view

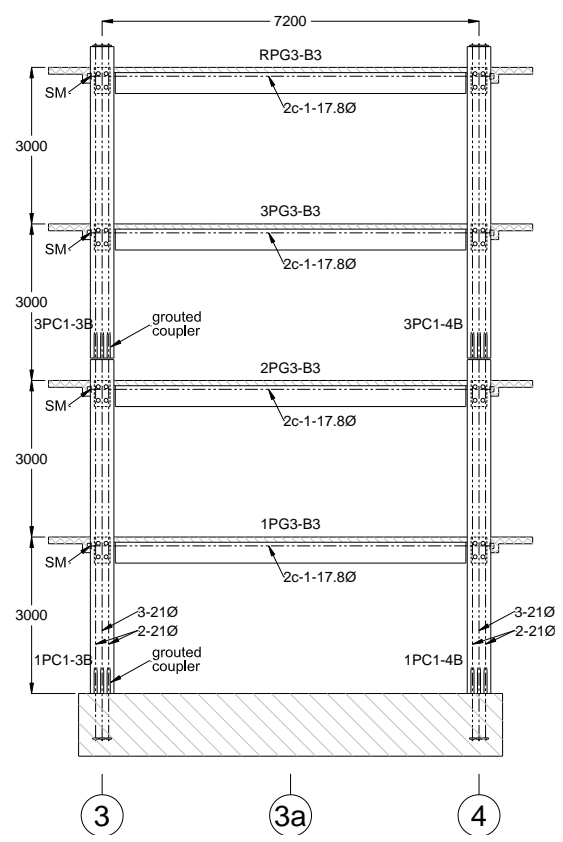

(c) Internal frame (grid B) tendon configuration as the grouted post-tensioned columns are unlikely to be utilised in New Zealand. As shown in Figure 2, the plan dimensions of the building were $14.4 \mathrm{~m}$ in the frame direction and $7.2 \mathrm{~m}$ in the wall direction, and included four stories with an inter-storey heights of $3.0 \mathrm{~m}$. Two-bay bonded posttensioned moment frames were used in the frame direction along gridlines 3 and 4. Unbonded post tensioned precast concrete walls with additional energy dissipation provided by mild steel reinforcement were used at each end of the building in the wall direction along gridlines $\mathrm{A}$ and $\mathrm{C}$. The wall design was typical of precast walls with hybrid connections involving unbonded post-tensioning and mild steel reinforcement and are referred to as Wall A and C. Unbonded post-tensioned beams spanned between the walls and columns at the corners of the building on gridlines A and C. A single bay moment frame was used along gridline $\mathrm{B}$ in the wall direction, as shown in Figure 2. Double-T precast floor units with a cast-insitu $100 \mathrm{~mm}$ topping were used for the floor system. At each storey the floor cantilevered out from the building perimeter between $0.35 \mathrm{~m}$ to $1.25 \mathrm{~m}$ using a cast-in-situ slab.

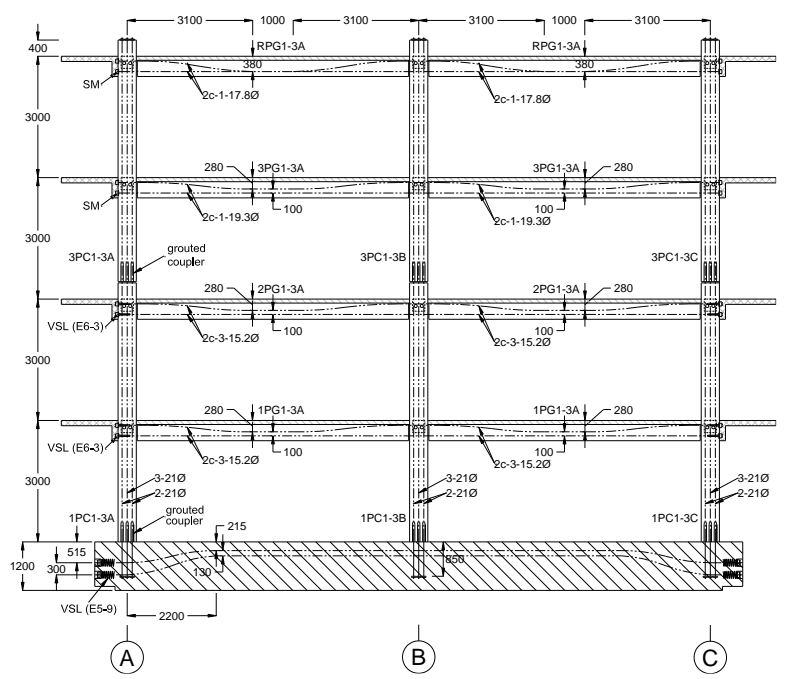

(b) Frame tendon configuration

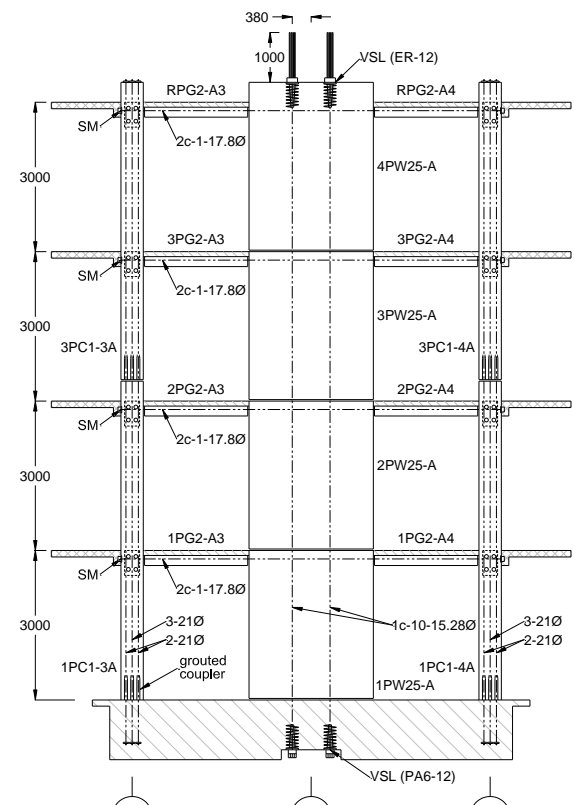

(3)

(3a)

(4)

(d) Wall A and C tendon configuration

Figure 2: Plan and elevation overview of test building (dimensions in $\mathbf{m m}$ ). 


\section{Walls}

The unbonded post-tensioned walls were $2500 \mathrm{~mm}$ long and $250 \mathrm{~mm}$ thick, as shown in Figure 3. Each of the two ducts contained ten $15.2 \mathrm{~mm}$ (SWPR7B) prestressing strands that were post-tensioned to $60 \%$ of their $1600 \mathrm{MPa}$ characteristic yield strength. The tendons were anchored underneath the foundation and on top of the roof wall panel that gave the tendons an unbonded length of $13,450 \mathrm{~mm}$. Eight $22 \mathrm{~mm}$ diameter (D22) mild steel reinforcing bars crossed the wall-tofoundation interface to provide additional energy dissipation and strength to the wall. The $22 \mathrm{~mm}$ diameter reinforcing bars were unbonded over a length of $1500 \mathrm{~mm}$ above the foundation interface to minimise inelastic strains and were terminated at the top of the first storey wall panel. The first storey wall panel used confinement reinforcement with a characteristic yield strength of $785 \mathrm{MPa}$ and spaced at $75 \mathrm{~mm}$ to resist the high compressive strains in the wall toe region. The concrete mix used in the first two storeys of wall A and the grout mix used between those panels and the wall-tofoundation joint contained steel fibres and all other concrete used conventional concrete mixes. The grout pad between the wall and foundation was $30 \mathrm{~mm}$ thick.

\section{Frames}

The beams in the wall direction were $300 \times 300 \mathrm{~mm}$ and utilised two $17.8 \mathrm{~mm}$ prestressing strands (SWPRL19L), as shown in Figure 4. The tendons were anchored on the external face of the exterior columns. The unbonded length for the tendons in both beams was $7650 \mathrm{~mm}$ as the tendons in PG2 beams passed through the horizontal ducts in the wall panel. The columns were $450 \times 450 \mathrm{~mm}$ with eight $21 \mathrm{~mm}$ diameter (SBPR1080/1230) prestressing bars. The beams in the frame direction were $500 \times 300 \mathrm{~mm}$ with four prestressing tendons within each beam that was anchored on the outside face of the exterior columns. The tendons used for the first and second, third and roof beams in the frame direction were, three 15.2 $\mathrm{mm}$ (SWPR7BL) strands, one $19.2 \mathrm{~mm}$ (SWPR19L) strand, and one $17.8 \mathrm{~mm}$ (SWPRL19L) strand, respectively. After post-tensioning the prestressing bar or tendon in the column and beams in the frame direction to $80 \%$ of the characteristic yield strength, the tendon ducts were filled with high strength grout. The characteristic yield stress of the prestressing strands was $1600 \mathrm{MPa}$ and the prestressing bar was $1080 \mathrm{MPa}$.

\section{Floors}

The Double-T precast pre-stressed concrete floor unit was $2000 \mathrm{~mm}$ wide and $200 \mathrm{~mm}$ deep, as shown in Figure 5. The floor units were placed parallel to the wall direction and were supported by the beams in the frame direction. The floor units had a seating length of $30 \mathrm{~mm}$ and were tied into the supporting beams via the $100 \mathrm{~mm}$ cast-in-situ topping with continuity reinforcement. A two-way mesh of $10 \mathrm{~mm}$ diameter reinforcement at $200 \mathrm{~mm}$ centers was placed within the castin-situ topping. Mechanical couplers were cast within the wall at $200 \mathrm{~mm}$ centers that $13 \mathrm{~mm}$ dowel bars screwed into and lapped with the floor reinforcement. The distance between the center of the first Double-T rib and the center of the wall was $600 \mathrm{~mm}$

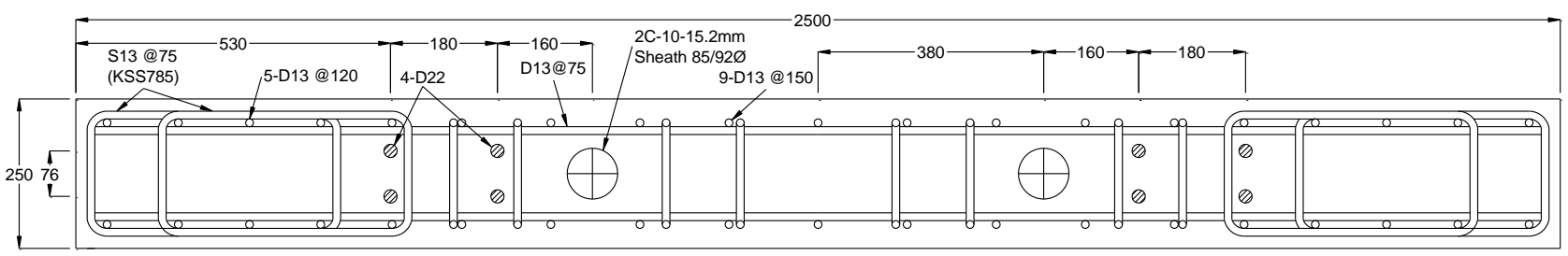

Figure 3: Wall A and C first floor cross-section (dimensions in mm).

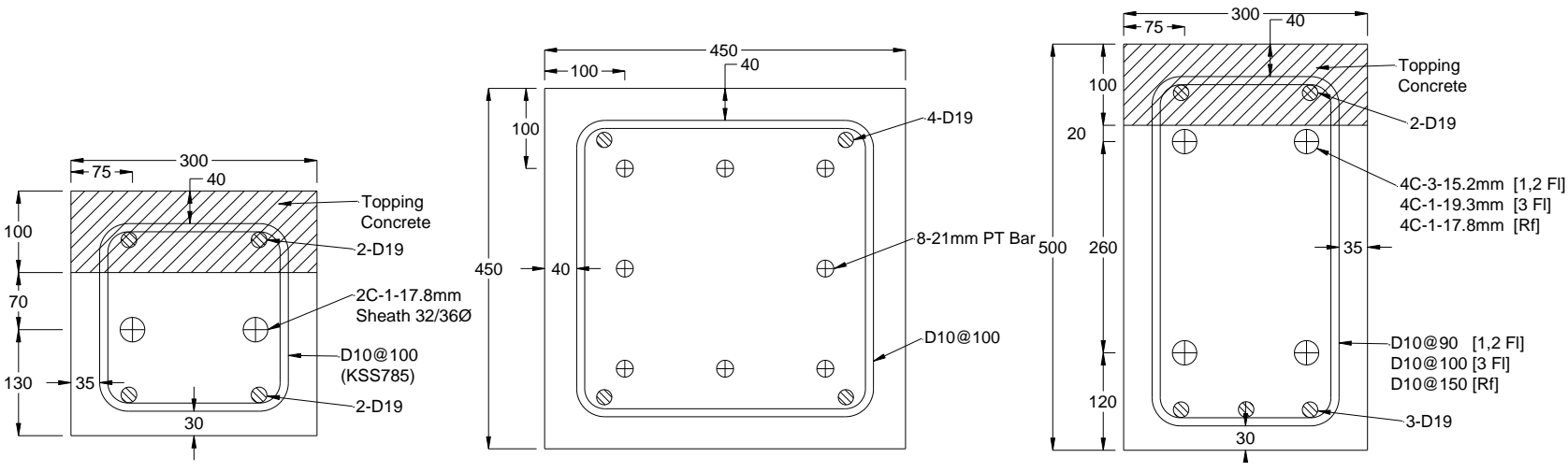

(a) Beam in wall direction

(b) Column

(c) Beam in frame direction

Figure 4: Column and beam cross-sections (dimensions in mm).

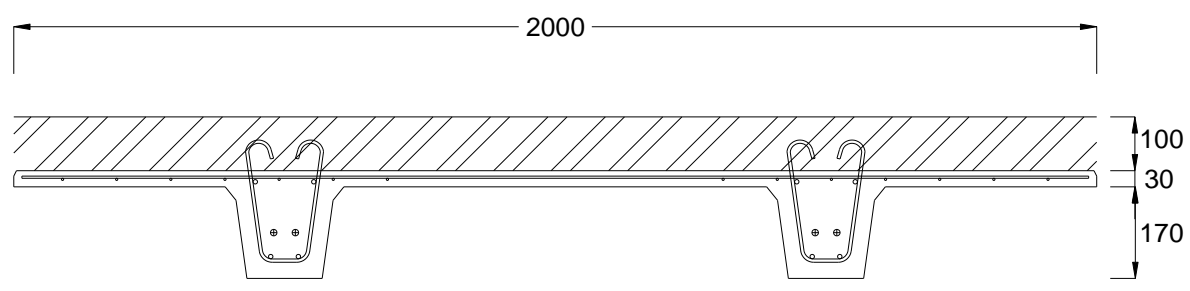

Figure 5: Double-T precast floor units cross-section c. 


\section{Material Properties and Weights}

The average strength of the precast concrete elements and the topping concrete at the time of testing was $83.2 \mathrm{MPa}$ and 40.9 $\mathrm{MPa}$, respectively. The total weight of the building was measured as $5356 \mathrm{kN}$ and the total effective weight of each storey was reported as $822 \mathrm{kN}$ (1st), $819 \mathrm{kN}$ (2nd), 822 (3rd), and $996 \mathrm{kN}$ (4th). The fourth floor was the heaviest due to approximately $200 \mathrm{kN}$ of equipment such as air conditioning units.

\section{Ground Motions}

The test building was subjected to increasing intensities of the strong motion records from the JMA-Kobe and JR-Takatori stations during the 1995 Kobe earthquake $\left(\mathrm{M}_{\mathrm{w}}=6.9\right)$. The table motions include 3-dimensional ground motion simulation, including both horizontal and vertical components. Figure 6 shows the 5\% elastic damped response spectra for observed table input motions in both horizontal directions compared to the NZS1170:5(2004) [17] spectral acceleration for a building in Wellington with Class D soil for a 2500 year return period. For the hypothetical building in Wellington, the Kobe $25 \%, 50 \%$, and $100 \%$ would correspond to a serviceability, ultimate and maximum credible earthquake respectively. Various instruments measured the buildings global and local response with the raw experimental data is available on NEES-hub [18]. Further details about the methodologies used to calculate the experimental responses from the raw data are reported in Watkins [20].

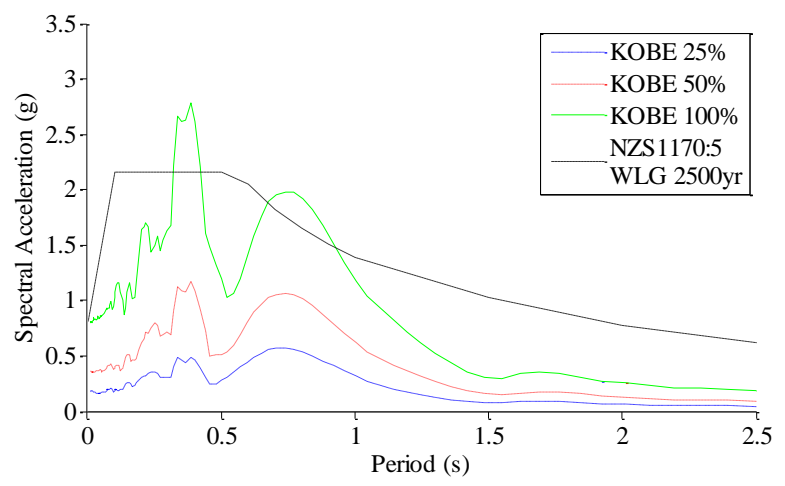

(a) Frame direction

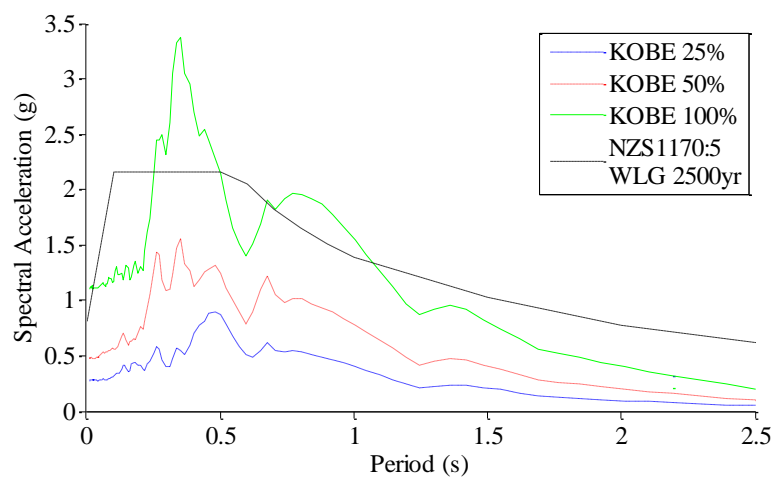

(b) Wall direction

Figure 6: Elastic response spectra (5\% damping) for table input motions.

\section{COMPUTATIONAL BUILDING MODEL}

A three dimensional graphical representation of the computational model developed for the building in SAP2000 v18.1.1 [19] is shown in Figure 7. The layout of the elements in the model used the building centerline dimensions that were shown in Figure 2. Descriptions of the main model features is provided with a more detailed account of the model development and validation published separately [20].

The elastic beam column elements representing the walls were $2500 \mathrm{~mm}$ in length, $250 \mathrm{~mm}$ in thickness and $3000 \mathrm{~mm}$ in height. A lumped plasticity fibre hinge section that behaved like a multi-spring macro model was used to capture the uplift and rocking at the wall base. This modelling technique has been previously validated against six isolated unbonded posttensioned wall tests [20]. The discretisation of the fibres in the fibre hinge representing the wall cross section is shown in Figure 8. Each fibre represented an area of the wall cross section at its base and was assigned the appropriate material model for that region of the wall. The energy dissipating reinforcing steel that was unbonded over $1500 \mathrm{~mm}$ at the base of wall $\mathrm{A}$ and $\mathrm{C}$ was also included as fibres within the fibre hinge. This approach has the same outcome as modelling the reinforcement as external elements because the displacement $1500 \mathrm{~mm}$ above the wall base is almost identical to the uplift at the wall base. The unbonded post-tensioned tendons in Wall $\mathrm{A}$ and $\mathrm{C}$ were fixed $1 \mathrm{~m}$ below the model's foundation level and connected to the wall $0.45 \mathrm{~m}$ above the roof, representing the anchorage conditions of the tendon in the building. The post-tensioning stress in the wall and beam tendons were simulated by applying an initial displacement to the non-linear truss elements an appropriate amount equal to the initial strain within the tendons.

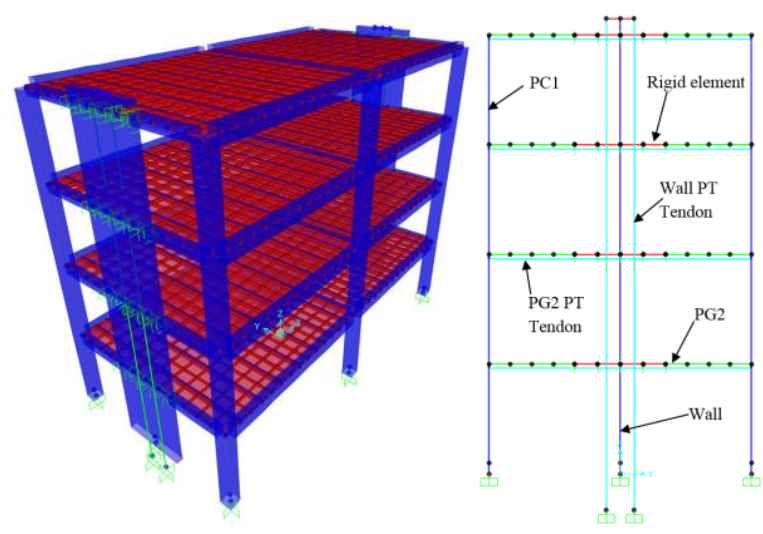

Figure 7: Computational model of the E-Defence building (a) three-dimensional model (b) elevation of grid $A$ and $C$.

To represent the width of the wall at each floor level, rigid elements were attached to the wall centreline element, as shown in red in Figure 7. These rigid elements had a stiffness ten times greater than the gross stiffness of the wall. The response of the post-tensioned beams in the wall direction was dominated by the rocking at the beam ends; therefore, the modelling method discussed for the wall was also used to represent the behaviour of these beams. The response of the frames in the wall direction was dominated by rocking of the column bases and beam ends, and hence, the modelling method used for the walls was used but with the prestress of the bonded tendons applied as an external axial load. During construction of the building the prestressing tendons in the column and beams in the frame direction were post-tensioned and then the tendon ends were anchored, and after this the tendon ducts were grouted. To represent this construction sequence in the model, axial loads that represented the posttensioning force were applied at the location of the tendon anchors. The bonded prestressing tendons were included in the fibre hinge section with their stress-strain backbone modified to account for the strain due to post-tensioning that was modelled by the external axial force. This method accounted for the axial force due to post-tensioning and the increase in the tendon strain due to rocking at the joint. 


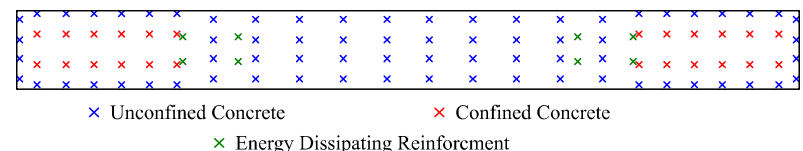

Figure 8: Wall A and C fibre discretisation.

In the frame direction, the moment demand in the column above and below the beam column joints exceeded the column's cracking moment capacity. A detailed moment curvature analysis was performed in Response 2000 [21] for the column cross-section including the $19 \mathrm{~mm}$ diameter mild steel reinforcement and bonded prestressing tendons with an initial strain representing the post-tensioning. The model moment-curvature hinge used the average column axial demand as the effect of the variation in axial load was explicitly accounted for by the fibre hinge at the base of the column. The plastic hinge length of the moment-curvature hinges was the same as the fibre hinge section at the column base and the hysteresis followed Takeda rules. The main purpose of these hinges was to capture the change in the columns flexural rigidity and had negligible effect of the hysteretic energy dissipated in the model. The moment demand on the columns in the wall direction did not exceed the column's cracking moment, however, the column had already experienced cracking due to the demand from the frame moment. Hence, the moment of inertia $\left(\mathrm{I}_{\mathrm{g}}\right)$ of the elastic beam column elements representing the columns flexural stiffness in the wall direction was reduced to $0.6 \mathrm{I}_{\mathrm{g}}$. The value of 0.6 was determined from the New Zealand Concrete Structures Standard, NZS 3101:2006 Table C6.6 [22] for a column with a normalised axial demand $\left(\mathrm{N}^{*} / \mathrm{Agf}\right.$ 'c) of approximately 0.17 .

Research by Arteta [23] and Welt [24] suggest that material regularisation is not required if the fibre hinge section height was equal to the damaged zone length where concrete spalling/cracking occur. Therefore, the fibre hinge lengths used for the model components was based on the observed damage to the test building, with the lengths/heights estimated from damage photographs [20]. This resulted in fibre hinge lengths of $250 \mathrm{~mm}$ for the walls, $120 \mathrm{~mm}$ for the beams in the wall direction, $200 \mathrm{~mm}$ for the beams in the frame direction, and $180 \mathrm{~mm}$ for the columns. The material model for the concrete within the fibre hinge sections did not have any tensile capacity as the concrete in a rocking joint only resists compression. Mander et al. [25] equations were used to define the backbone stress-strain curves for all the concrete material models. The ultimate confined concrete strain was calculated using an equation provided by Moehle's and Arteta [23, 26]. The hysteretic behaviour of all concrete elements in the model was governed by Takeda [27] rules. The Holzer et. al. [28] equation was used to define all the reinforcement stress-strain backbones used in the model and the hysteretic behaviour of the reinforcement stress-strain models was governed by kinematic rules. The stress-strain backbone of all the prestressing tendons was defined by Devalapura and Tadros [29]. Further details about the material parameters used in the model reported in Watkins [20].

To investigate the wall-to-floor interaction, the non-linear behaviour of the floor in both the in-plane and out-of-plane directions needed to be included. The floor was represented by non-linear layered shell elements meshed at approximately $500 \times 500 \mathrm{~mm}$; a detailed sensitivity study verified that further discretisation did not yield additional accuracy. The concrete shell layer was $130 \mathrm{~mm}$ thick and had five integration points through its thickness. The combined thickness of the in-situ topping and Double-T flange was used as no evidence of delamination between the two elements was observed during the test. The material model used for the concrete layer within the shell elements accounted for crack formation and rotation.
The concrete material model was a modified implementation of the two-dimensional Darwin-Pecknold [30] co-axially rotating smeared crack concrete material model. Darwin and Pecknold's original model was modified to include Vecchio and Collins [31] Modified Compression-Field Theory that accounts for compressive strength reduction based on perpendicular tensile strain. The in-plane behaviour of the floor's two way $10 \mathrm{~mm}$ diameter reinforcement mesh spaced at $200 \mathrm{~mm}$ was represented in the model by two smeared membrane layer. Bond slip and dowel behaviour of the floor reinforcement was not considered within the layered shell element as this was modelled separately for the wall-to-floor connection detail. The dowel bar connection between the floor and wall was modelled by zero length non-linear links using a bi-linear relationship proposed by $\mathrm{He}$ and Kwan [32]. The stiffness of the Double-T ribs was considered important and thus the ribs were represented by elastic-beam column elements that were pinned at their connection to the beams in the frame direction to represent that they were only vertically supported by a short ledge on these beams in the building.

The damping a building experiences when subjected to earthquake excitation originates from many different sources that can be broadly categorised as either viscous or hysteretic damping. In the computational model hysteretic damping was explicitly captured through the use of non-linear material behaviour assigned to the fibres within the fibre hinge sections. Initial stiffness Rayleigh proportional damping was used to capture the viscous damping. Viscous damping was assumed to be $2.5 \%$ as per the procedure recommended by Pennucci et. al. [33]. Shake table tests conducted by Twigden [7] and Nazari [34] both confirmed recommended damping of $2 \%$ for accurate non-linear time history analysis of isolated rocking walls. Therefore, an increase in damping to $2.5 \%$ was considered reasonable for a computational model that considered the entire building where additional sources of damping were present.

Two additional modifications were made to the damping scheme in order to avoid factitious damping forces when using initial stiffness Rayleigh damping. First, any element in the model that had a high initial stiffness and was expected to yield was assigned a stiffness proportion damping constant a scaled by $1 / 50$. This mimicked the updated tangential stiffness behaviour for yielding elements (a feature not available in SAP 2000). Second, period elongation was considered so that damping is not over-estimated as inelastic behaviour and damage occurred. The initial period in the wall direction was $0.29 \mathrm{~s}$ and the elongated period in the frame direction was $0.86 \mathrm{~s}$ which resulted in $\alpha_{0}$ and $\alpha_{1}$ values of 0.2732 and 0.0017 , respectively. Where $\alpha_{0}$ and $\alpha_{1}$ are the mass and stiffnessproportional damping coefficient used in determining the initial stiffness Rayleigh damping matrix.

\section{MODEL RESULTS AND DISCUSSION}

The building model was subjected to the Kobe $25 \%$, Kobe $50 \%$, and Kobe $100 \%$ shake table accelerations consequently (as was done during testing). The results presented focuses on the wall direction response as the design used for the frame direction, in particular the columns, are not considered representative of New Zealand practice.

\section{Modal Properties}

As discussed by Nagae et. al. [12], the test building exhibited a significant torsional response during all the imposed earthquake motions. The modal properties of the test building before being subjected to earthquake motions were investigated during this study to find a possible explanation for the observed torsional behaviour. Examination of the actuator displacements showed there was negligible twisting 
of the shake table. Analysis of the accelerations measured at the accelerometer locations when the building was subjected to white noise at the beginning of the experimental test program found that in the wall direction the ends of the building were excited with different magnitudes, at the fourth floor Wall C displaced 24\% further than Wall A. A detailed examination of the concrete strength at the time of testing for the wall panels revealed that three out of the four wall panels in Wall $\mathrm{C}$ had an average concrete strength of $72 \mathrm{MPa}, 15.5 \%$ less than the average concrete strength of $83.2 \mathrm{MPa}$ used for other precast elements. When the modulus of elasticity of wall $\mathrm{C}$ was adjusted to represent the lower concrete strength, the model accurately captured the measured first mode shape in the wall direction and fundamental period of $0.29 \mathrm{~s}$, as shown in Figure 9a.
In the frame direction, the building's accelerometers were all aligned along gridline $3 \mathrm{~A}$. Analysis of the accelerations in the frame direction can only produce the normalised mode shape at the building's center and not at each of the perimeter frames. The model accurately captured the experimental frame direction normalised mode shape and fundamental period of $0.45 \mathrm{~s}$, as shown in Figure 9b.

The acceleration history of the earthquake records could also activate a torsional mode of the building. Analysis of the building response during the white noise test did detect a purely torsional mode with a measured period of $0.21 \mathrm{~s}$. The building model accurately captured the torsional model period and normalised mode shape, as shown in Figure 9c. However, it is difficult to determine if this elastic torsional mode was activated during earthquake motions as the building's inelastic response changed its stiffness.

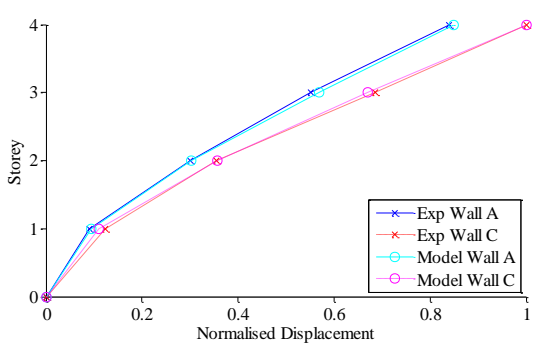

(a) wall direction

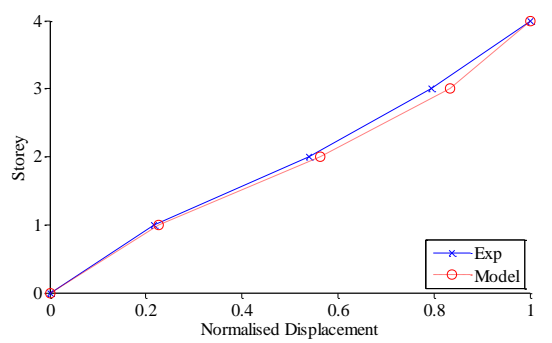

(b) frame direction

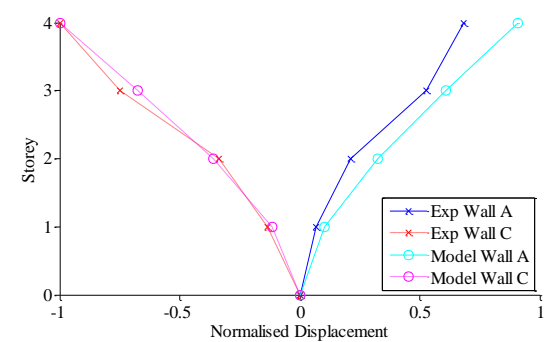

(c) torsional

Figure 9: Comparison between test and model initial modal shapes.

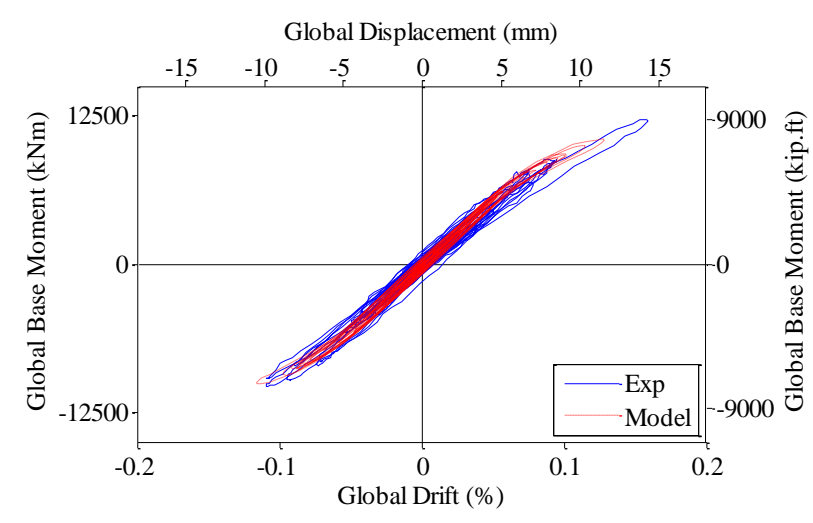

Figure 10: Comparison between experimental and model global response in the wall direction for Kobe 25\% (a) moment-drift response (b) drift response (c) moment response (d) shear response).

\section{Global Response}

A comparison between the experimental and model global building response in the wall direction during Kobe $25 \%$ is shown in Figure 10, where global drift is defined as the displacement at the center of the third floor in the wall direction. There was good agreement between the experiment and model for the global drift, base moment and base shear response from the start of the test up until 18s. During this time range the model accurately captured the measured peak drifts of $0.095 \%$ and $-0.1 \%$. The model also accurately captured the measured peak base shear and moment capacity of $8933 \mathrm{kNm}$ and $1126 \mathrm{kN}$, respectively. Between 18s and 20.8 s the model drifts shifted out of phase when compared to the experimental response, and the large excursion to $0.16 \%$ drift was not accurately captured. After 20.8 s the model response returned to being in-phase with the experimental response with close correlation. There was good agreement between the experiment and model for the global base moment versus drift response. The experimental hysteretic cyclic response was well captured by the model, with only minimal energy dissipation occurring.

A comparison between the experiment and model global building response in the wall direction during Kobe $50 \%$ is shown in Figure 11. There was good agreement between the experimental and model global drift, moment and shear response except for a couple of cycles. The model accurately calculated the initial peak drift of $0.21 \%$ at $14.5 \mathrm{~s}$, and the peak drifts at $17.5 \mathrm{~s}$ and $17.7 \mathrm{~s}$ of $-0.36 \%$ and $0.28 \%$, respectively. The model was unable to capture the large excursion to $0.51 \%$ drift at $18.14 \mathrm{~s}$, instead it estimated a drift of $0.33 \%$. However, the model accurately captured the building self-centering capability at the end of the test with no significant residual 
displacement. Commencement of wall uplift occurred at $14.4 \mathrm{~s}$, as defined by an in-plane wall rotation greater than 0.001 radians. The peak measured base moment of $-19,380 \mathrm{kNm}$ and base shear of $2250 \mathrm{kN}$ were accurately captured by the model. There was generally good agreement between the experiment and model for the global base moment versus drift response. The model's hysteretic moment-drift response accurately captured the experimental energy dissipated during the Kobe $50 \%$ test and the model also accurately captured the softening response of the building due to rocking at the wall base.

A comparison between the experiment and model global building response in the wall direction during the Kobe 100\% test is shown in Figure 12. There was generally good agreement between the experimental and model global drift versus time response from the start of the test up until $16.5 \mathrm{~s}$. The model over-estimated the measured drift at $15.5 \mathrm{~s}$, but its peak closely matched the peak measured drift of $1.6 \%$ that occurred at 20.1s.

Between $16.5 \mathrm{~s}$ and $19.5 \mathrm{~s}$, there was some agreement between the model and experimental drift response, although the model response was out-of-phase. After 19.5s the model did not

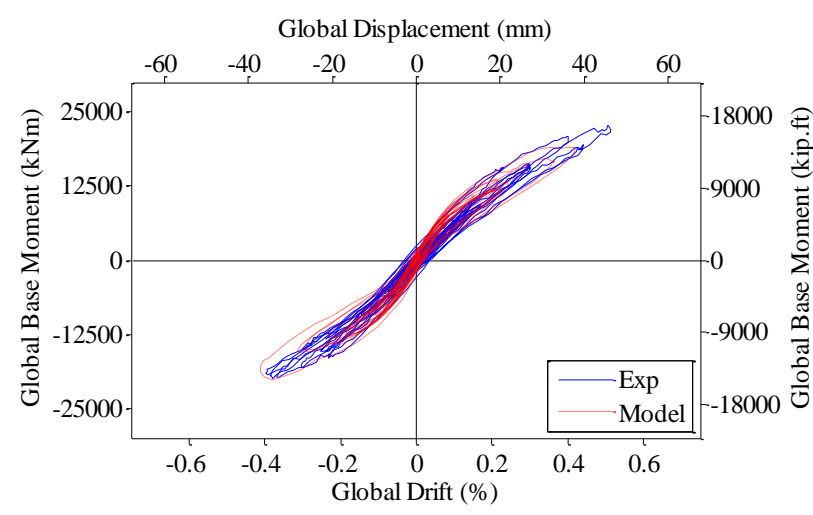

Figure 11: Comparison between experimental and model global response in the wall direction for Kobe 50\% (a) moment-drift response (b) drift response (c) moment response (d) shear response).
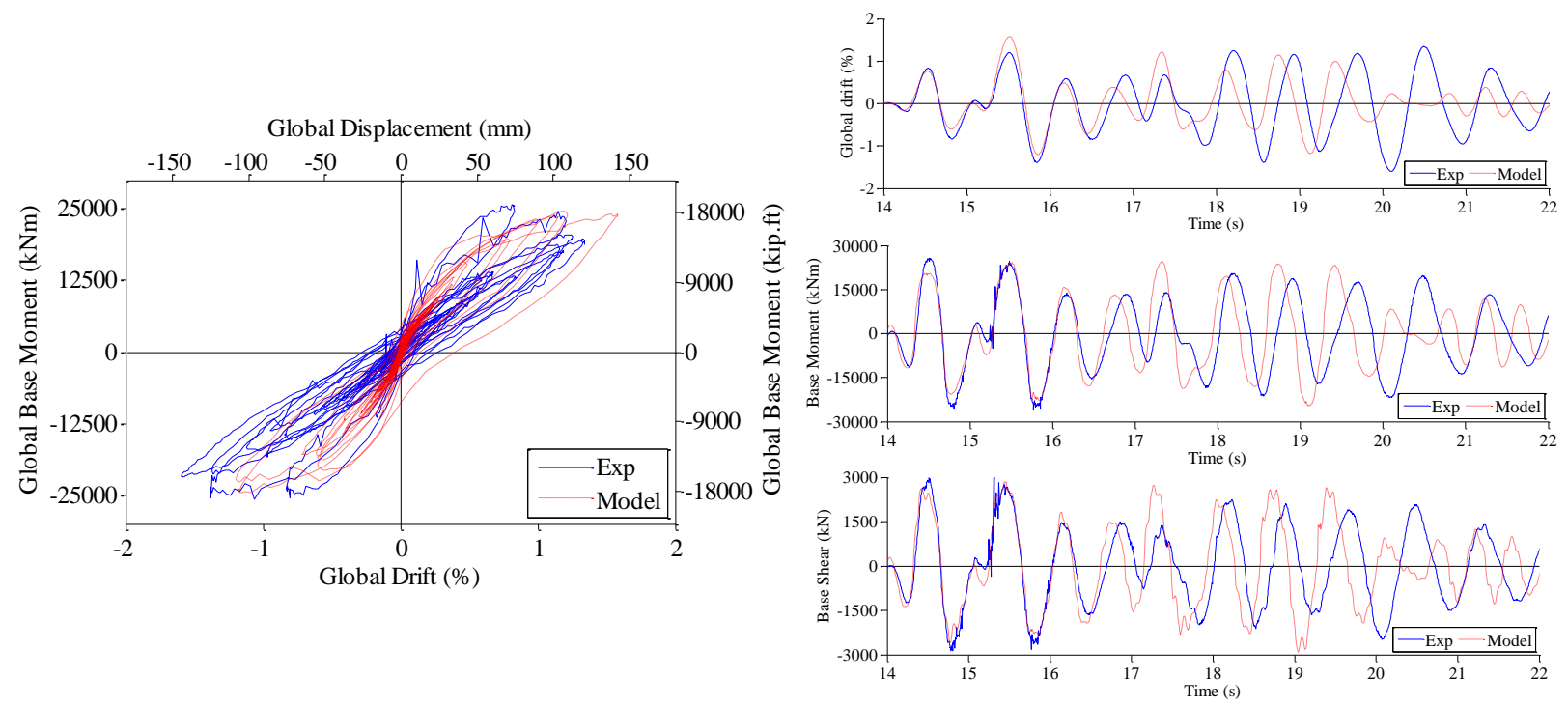

Figure 12: Comparison between experimental and model global response in the wall direction for Kobe 100\% (a) moment-drift response (b) drift response (c) moment response (d) shear response). 

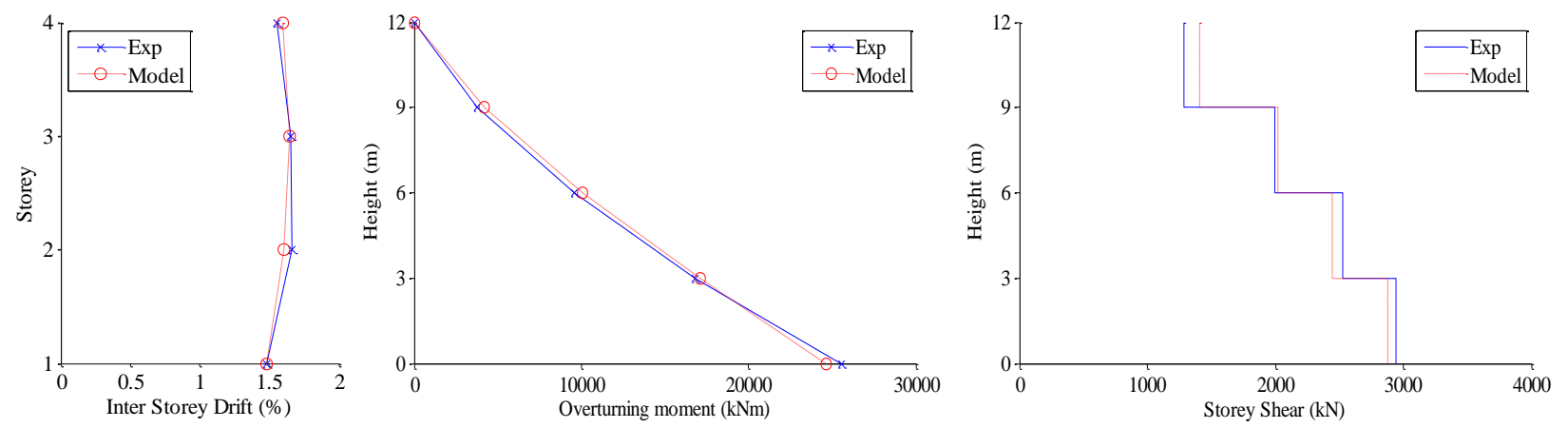

Figure 13: Comparison between experimental and model envelope responses for Kobe 100\% (a) inter-storey drift (b) overturning moment (c) storey shear.

\section{Strength Components}

Table 1 reports the contribution of various lateral-resisting systems at $1 \%$ drift in the wall direction of the building when subjected to a uni-directional push-over and from Kobe $100 \%$ test between $18 \mathrm{~s}$ to $19 \mathrm{~s}$, full details of this analysis are reported in Watkins [20]. Exterior and Interior framing action refer to the outrigger effect of beam shears transferred into the exterior and interior columns. Theoretically the global base moment from this framing action is the number of stories multiplied by the over-strength shear capacity of the rocking joint at the beam-column interface multiplied by the distance between the exterior or interior columns. Furthermore, the exterior boundary beams that frame into the edges of the wall provided additional moment capacity to the wall system through framing action. The increase in wall system moment capacity from the boundary beams increased the lateral force required to obtain the same uplift as an equivalent wall system without boundary beams framing into the wall ends. In the case of the building modelled this restraint was not sufficient to prevent the wall uplifting. The computational model incorporated the moment capacity of the framing beams and therefore captured the restraint on uplift of the wall. Table 1 shows the exterior columns had a 57\% reduction in their moment capacity primarily due to the large dynamic bidirectional rotational demands imposed upon them that resulted in significant spalling of concrete at the column base. While the interaction effects increased the axial demand at the base of the columns, the large rotations caused the spalling of concrete and reduced moment capacity. The walls experienced some cyclic degradation; dynamic loading and interaction effects resulted in a $25 \%$ increase in the base moment contribution from the exterior framing action in the wall direction.

\section{Stiffness Degradation}

The modal periods corresponding to the first mode in the wall direction before and after the Kobe $100 \%$ test for the experiment and model are reported in Table 2. The model did not capture the period elongation that occurred during the Kobe 50\% test; reasons for this include not capturing the peak excursion to $0.51 \%$ drift and micro-cracking of the concrete elements and grout pad. However, it correctly estimated the magnitude of the period elongation during the Kobe $100 \%$, which was equal to approximately $40 \%$. The model captured approximately $45 \%$ of the measured torsional rotation during all three earthquake tests except after $17 \mathrm{~s}$ during the Kobe $100 \%$ test. Investigation of the measured accelerations records suggested that after $17 \mathrm{~s}$ the building torsional mode was resonating with the input excitation resulting in a peak torsional rotation of 0.0082 radians. Furthermore, the grout pad underneath wall $\mathrm{C}$ experienced significant damage at its ends due to the lack of steel fibres (which wall A grout pad had) and it is probable that this damage contributed to the large torsional rotations observed.
Table 1: Wall direction global base moment contributions at $1 \%$ drift.

\begin{tabular}{|l|c|c|c|}
\hline & $\begin{array}{c}\text { Model } \\
\text { Push } \\
(\mathbf{k N m})\end{array}$ & $\begin{array}{c}\text { Model EQ } \\
(\text { Kobe 100\%) } \\
(\mathbf{k N m})\end{array}$ & $\begin{array}{c}\text { Increase } \\
\text { (\%) }\end{array}$ \\
\hline Walls & 11,658 & 10,120 & -13.2 \\
\hline Exterior columns & 2,131 & 911 & -57.3 \\
\hline Interior columns & 1,051 & 532 & -49.4 \\
\hline $\begin{array}{l}\text { Exterior Framing } \\
\text { action }\end{array}$ & 7,550 & 9,468 & 25.4 \\
\hline $\begin{array}{l}\text { Interior Framing } \\
\text { action }\end{array}$ & 2,195 & 3,440 & 56.7 \\
\hline Total & 24,585 & 24,471 & -0.4 \\
\hline
\end{tabular}

Table 2: First mode periods in wall direction.

\begin{tabular}{|l|l|l|l|}
\hline & \multicolumn{1}{|c|}{ Initial } & \multicolumn{1}{|c|}{$\begin{array}{c}\text { After Kobe } \\
\mathbf{5 0} \%\end{array}$} & \multicolumn{1}{|c|}{$\begin{array}{c}\text { After Kobe } \\
\mathbf{1 0 0 \%}\end{array}$} \\
\hline Experiment & $\mathbf{0 . 2 9 \mathrm { s }}$ & $\mathbf{0 . 3 7 \mathrm { s }}$ & $\mathbf{0 . 5 2 \mathrm { s }}$ \\
\hline Model & $\mathbf{0 . 2 9 \mathrm { s }}$ & $\mathbf{0 . 2 9 \mathrm { s }}$ & $0.40 \mathrm{~s}$ \\
\hline
\end{tabular}

\section{Wall Response}

The comparison between the moment-drift response of each wall during Kobe $100 \%$ in both the in-plane and out-of-plane directions are shown in Figure 14. There was good agreement with the base moment capacity, but each wall was subjected to different displacement demands due to the buildings torsional rotation. The out-of-plane moment capacity of the walls was approximately $3.5 \%$ of their in-plane capacity; a similar proportion to an isolated bi directional wall test that is discussed by Watkins [20].

A comparison of the uplift at the ends of wall $\mathrm{A}$ and $\mathrm{C}$ for both the experiment and model are shown in Figure 15. The model accurately captured the uplift at the wall ends for both walls. The experimental peak rotation and uplift for wall $\mathrm{C}$ was under estimated by the model as the model only captured approximately $50 \%$ of the torsional rotation, as discussed previously. A comparison of the axial force in the prestressing tendons of wall $\mathrm{C}$ from the test and model are shown in Figure 16. The model accurately captured the experimental response except for the peak rotation and axial force, which the model under estimated due to only capturing approximately $50 \%$ of the building's torsional rotation. The prestressing tendons were initially post-tensioned to $60 \%$ of their characteristic yield strength, and at the peak wall rotation the stress of tendon 1 was $71.5 \%$ of its measured yield strength $\left(\mathrm{f}_{\mathrm{y}}=\right.$ $1760 \mathrm{MPa}$ ). Hence, the prestressing tendons in the wall remained in their elastic range which allowed the building to self-center in the wall direction after the earthquake motion. 


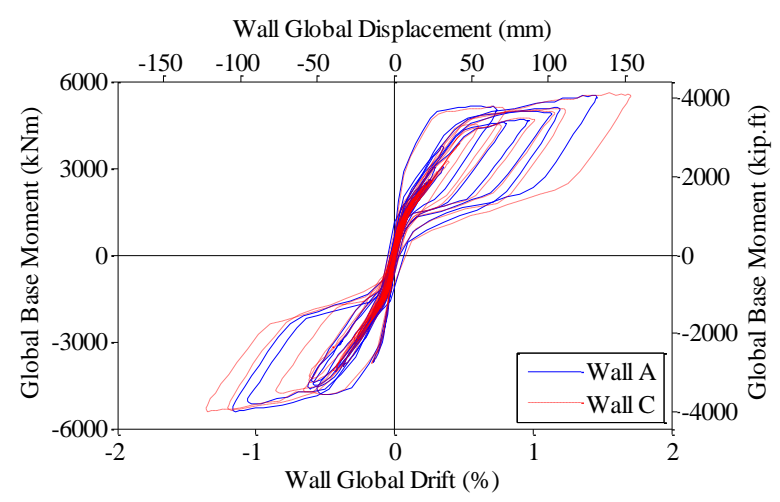

(a) in-plane direction

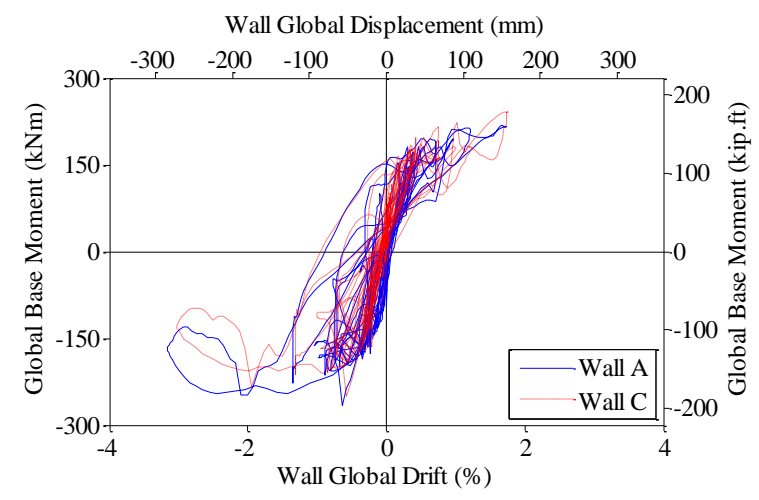

(b) out-of-plane direction

Figure 14: Comparison between the wall base moment-drift responses for Kobe $100 \%$.

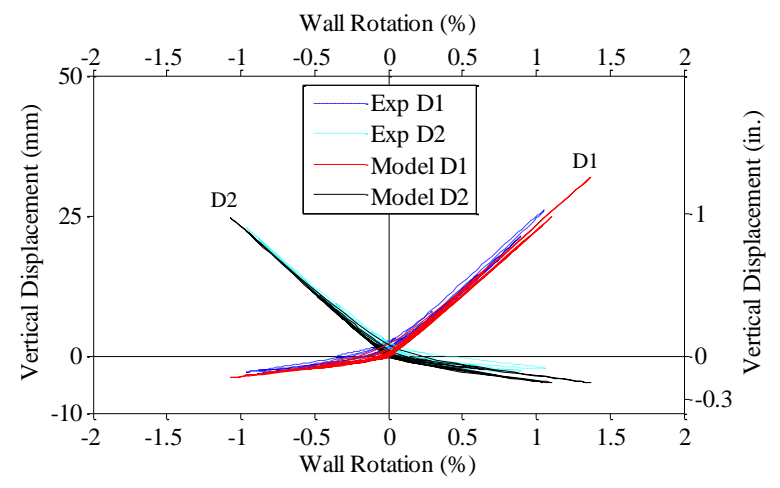

(a) wall A

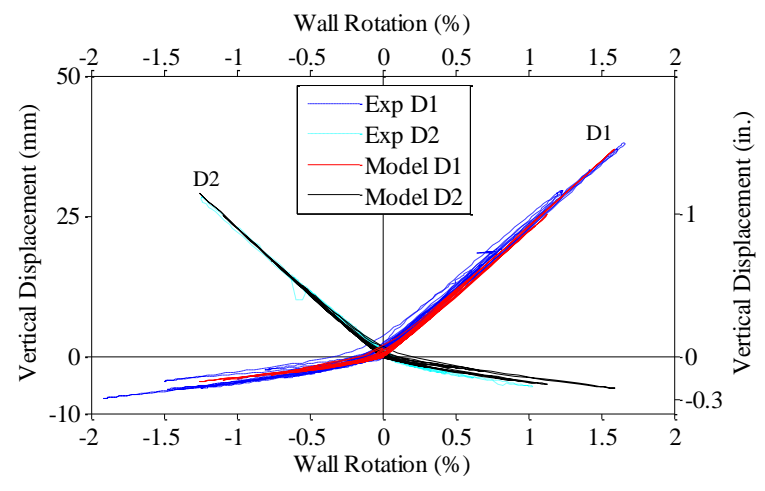

(b) wall C

Figure 15: Comparison between experimental and model wall base uplift for Kobe 100\%.

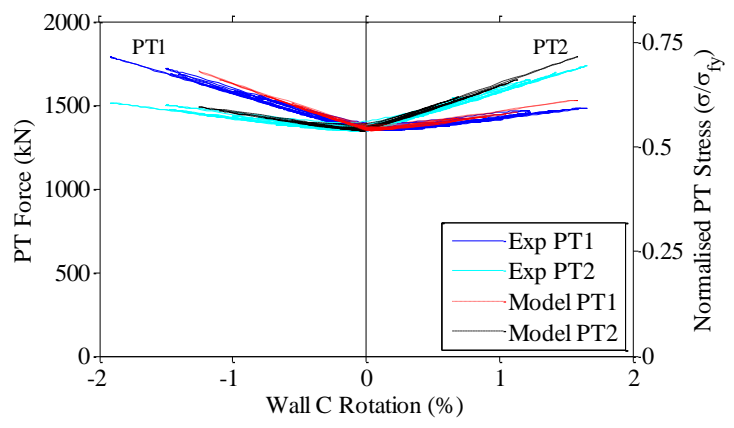

Figure 16: Comparison between experimental and model wall C PT axial force for Kobe 100\%.

The effect of dynamic loading on the wall axial force and base shear was investigated by comparing the response of the model subjected to a uni-directional pushover to the Kobe $100 \%$ earthquake record. As shown in Figure 17, there was good agreement between the two model responses when considering wall axial force, which was expected as almost all of the axial force imposed on the wall is due to the prestressing. However, there were significant differences between the base shear generated in wall A for the two loading types, as shown in Figure 18. The peak base shear demand for wall A during Kobe $100 \%$ was $1262 \mathrm{kN}$ at a wall A global drift of $1.3 \%$, and at the same drift the base shear demand was $880 \mathrm{kN}$ for the model pushover analysis. Therefore, dynamic loading increased the base shear demand of wall A by $43 \%$ when compared to the same model subjected to a pseudo-static uni-directional pushover analysis. In accordance with the New Zealand Concrete Structures Standard [22] (NZS 3101:2006) a dynamic shear magnification factor of 1.3 would apply to the test building (Appendix CD4.3), which slightly underestimated the measured amplification. The building model peak wall base shear during the Kobe $100 \%$ earthquake was $110 \%$ greater than the same building model, which did not consider the wall-to-floor interaction or dynamic loading. Therefore, guidance is still required to assess the likely overstrength resulting from wall-to-floor interaction. It is important to note that the effect of wall-to-floor interaction increasing the wall base shear demand has the potential to be more severe for reinforced concrete walls. The reinforced concrete building with identical geometry tested adjacent to the post-tensioned building on the E-Defence shake table experienced shear sliding at the base of its walls [35], and it was noted the actual base shear demands were much higher than calculated, although these increased demands were less than the walls theoretical capacity to resist shear sliding. The results of the post-tensioned building model would strongly suggest the increase in the reinforced concrete wall base shear demands were due to wall-to-floor interaction. If the over-strength effect of wall-to-floor interaction is not accounted for in the capacity design process, undesirable failure modes, such as shear sliding may occur.

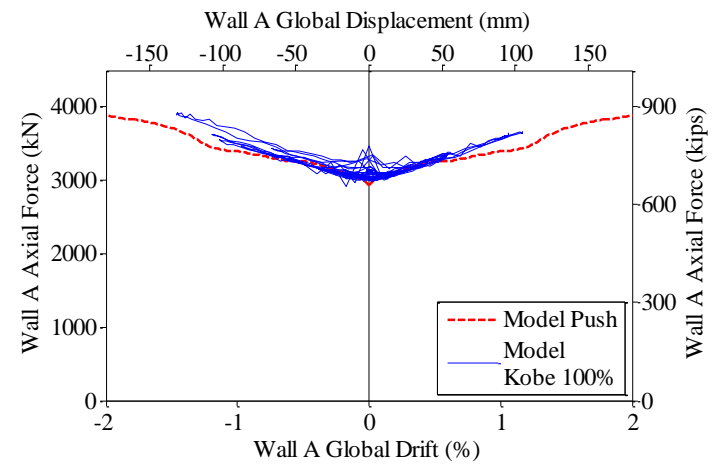

Figure 17: Comparison between model subjected to pushover and Kobe $100 \%$ for wall A axial force-drift response. 


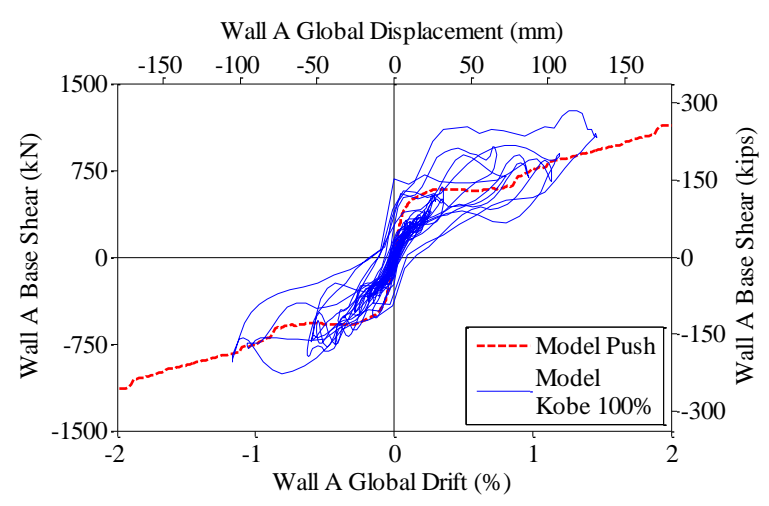

Figure 18: Comparison between model subjected to pushover and Kobe $100 \%$ for wall A base shear force-drift response.

\section{Beam Response}

A comparison of the neutral axis length response for the beam on the first storey between wall $\mathrm{C}$ and grid 3 from both the test and model are shown in Figure 19. There was good agreement between the model and experimental response and the model accurately captured the effect that the floor slab had on the neutral axis length of the beams in the wall direction. The beam rotated further in the positive direction as this was the direction that the wall uplifted at the beam end measured. A compressive force in the floor slab was developed when the beam rotated in the positive direction which reduced the neutral axis length. When the beam was subjected to negative rotations, the floor was in tension and increased the compression forces and neutral axis length of the beam.

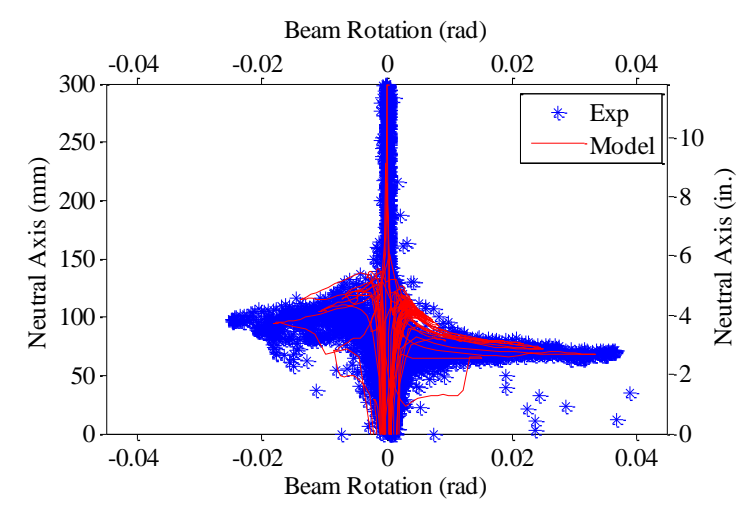

Figure 19: Comparison between experimental and model for neutral axis length-drift response for first storey beam in wall direction during Kobe $100 \%$.

\section{Floor Response}

A plan view of the building with contours representing the first storey vertical displacements from the model during Kobe $100 \%$ at $14.54 \mathrm{~s}$ is shown in Figure 20. The vertical uplift of wall $\mathrm{A}$ and $\mathrm{C}$ subjected a localised floor region around the wall edge to significant vertical displacements. Approximately $50 \%$ of the vertical displacement imposed on the floor by wall uplift was accommodated by local deformation for the floor slab between the wall and first Double-T rib $(\sim 600 \mathrm{~mm})$. Perpendicularly further out from wall $\mathrm{A}$, there was no discernible vertical displacement. However, near gridline C, the edge of the uplifting column subjected the length of the building in the wall direction to vertical displacements. Also the floor region to the left of the interior columns was uplifted along the length of the building in the wall direction, as highlighted in the figure. A comparison between the experiment and model vertical displacement of the first storey floor at various locations during Kobe $100 \% 14.54 \mathrm{~s}$, is shown in Figure 21. The figure shows the model accurately captured the measured floor vertical displacements, which provides further validation that the building model developed can capture both the in-plane and out-of-plane floor behaviour and effects of wall-to-floor interaction.

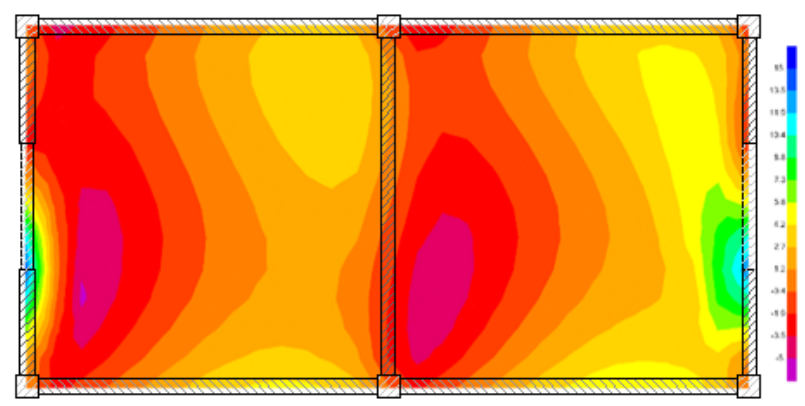

Figure 20: Model second storey floor vertical displacements (in mm) at 14.54s during Kobe 100\%.

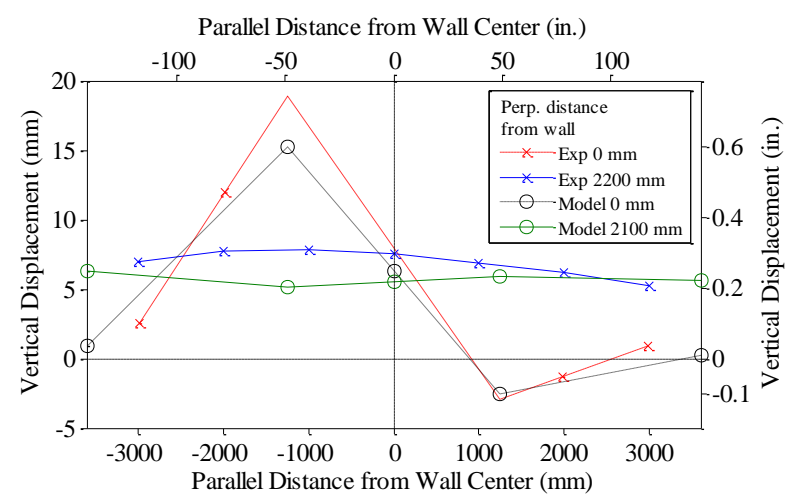

Figure 21: Comparison between experimental and model for second floor vertical displacement during Kobe $100 \%$ at $14.54 s$.

The components of lateral-load resistance for the building model subjected to a uni directional pushover in the wall direction at $1 \%$ drift are reported in Table 3 . The models floor behaviour was modified so that it used a rigid diaphragm type constraint (no floor), in-plane floor behaviour (membrane), and in-plane and out-of-plane behaviour (shell). Further information about these different techniques of modelling the floor is reported in Watkins [20]. The reported results show that in-plane and out-of-plane floor behaviour contributed to an increase in the buildings lateral load capacity of $2,482 \mathrm{kNm}$ $(14 \%)$ and $4,883 \mathrm{kNm},(28 \%)$ respectively. The vertical deformation of the floor contributed approximately two-thirds of the additional lateral-load resistance and the elongation or shortening of the floor contributed the remaining third. The increased lateral strength highlighted the importance of considering the wall-to-floor interaction and non-linear behaviour of the floor diaphragm.

Table 3: Wall direction global base moment contributions at $1 \%$ drift for the building model.

\begin{tabular}{|l|c|c|c|}
\hline & $\begin{array}{c}\text { No floor } \\
(\mathbf{k N m})\end{array}$ & $\begin{array}{c}\text { Membrane } \\
\text { floor }(\mathbf{k N m})\end{array}$ & $\begin{array}{c}\text { Shell floor } \\
\mathbf{( k N m )}\end{array}$ \\
\hline Walls & 11,219 & 11,305 & 11,658 \\
\hline $\begin{array}{l}\text { Exterior } \\
\text { columns }\end{array}$ & 2,207 & 2,197 & 2,131 \\
\hline Interior columns & 1,065 & 1,064 & 1,051 \\
\hline $\begin{array}{l}\text { Exterior } \\
\text { Framing action }\end{array}$ & 2,409 & 3,989 & 7,550 \\
\hline $\begin{array}{l}\text { Interior Framing } \\
\text { action }\end{array}$ & 320 & 1,147 & 2,195 \\
\hline Total & 17,220 & 19,702 & 24,585 \\
\hline
\end{tabular}




\section{Column Response}

A comparison of the column base moment response from the model during Kobe $100 \%$ and the model subjected to a unidirectional pushover analysis are shown in Figure 22. In the frame direction, the envelope of the time-history model response had some agreement with the pushover response; however, in the wall direction the time-history model response envelope was significantly less than the pushover response due to the bi-axial moment demands. The effect that dynamic loading had on the column axial force was investigated by comparing the response of the model subjected to a unidirectional pushover and to the Kobe $100 \%$ earthquake record. There were significant differences between the axial load in the external column for the different model loading conditions, as shown in Figure 23. The maximum and minimum axial force for the exterior columns during the Kobe 100\% earthquake were $3741 \mathrm{kN}$ and $1471 \mathrm{kN}$. The equivalent axial forces at $1.5 \%$ wall drift estimated by the pushover model were $3267 \mathrm{kN}$ and $1961 \mathrm{kN}$, respectively. Therefore, the dynamic loading increased and decreased the maximum and minimum axial force estimated by the pushover analysis by $15 \%$ and $25 \%$, respectively. Dynamic magnification for column axial forces is currently not explicitly prescribed in the New Zealand Concrete Structures Standard [22] (NZS 3101:2006). Based on these results, it appears that the dynamic magnification of column axial forces should be included as part of the capacity design process.

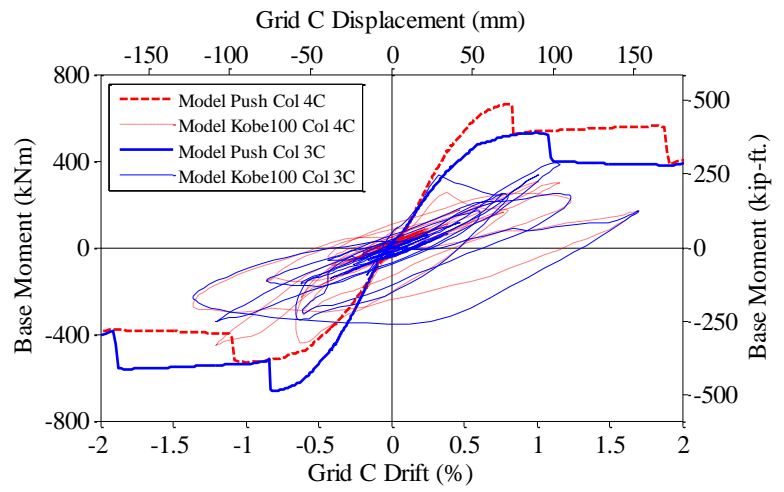

(a) wall direction

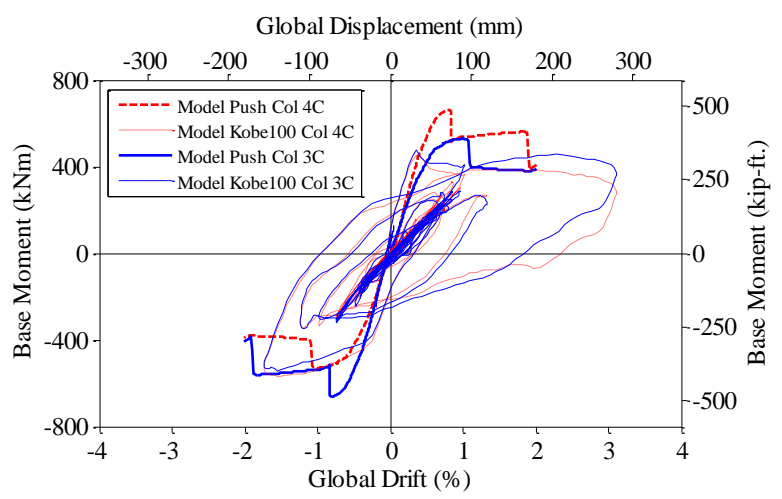

(b) frame direction

Figure 22: Comparison between experimental and model column base moment-drift response for Kobe 100\%.

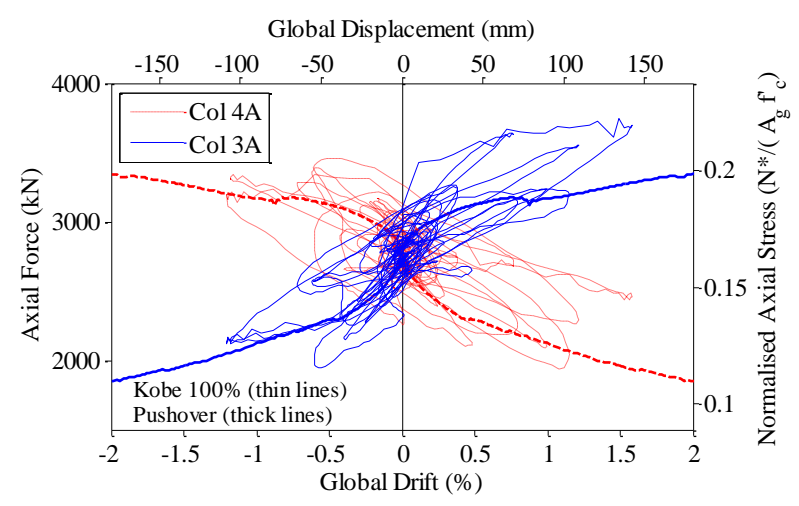

(a) wall direction

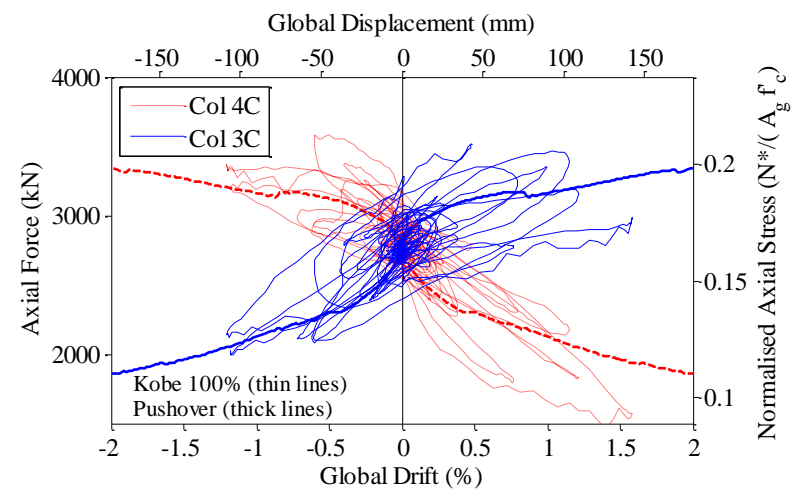

(b) frame direction

Figure 23: Comparison between model subjected to pushover and Kobe $100 \%$ for external column axial force-drift response.

After the Kobe $100 \%$ test, significant damage was observed at the base of the corner columns, as shown for column $4 \mathrm{C}$ in Figure 24, and the damage shown was typical for the base of all the test building columns. Most of the cover concrete at the column base had spalled, exposing the transverse reinforcement and some of the prestressing bar ducts. The local response of the column bases was investigated to understand how this damage occurred. In both the experiment and model, the peak column base rotation in the frame direction was approximately $4 \%$. The large rotations in conjunction with the axial force caused high strains in the cover concrete zone, causing that region to spall excessively. After the concrete spalled, the flexural rigidity of these columns was greatly reduced, making their base connection to be more like a pin support than a fixed support.

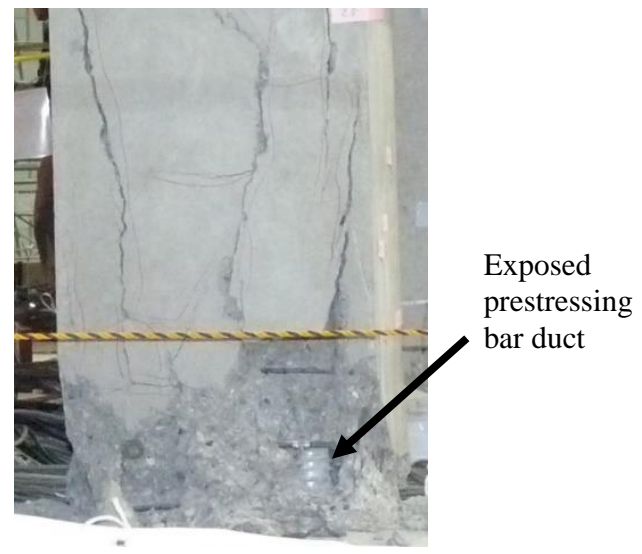

Figure 24: Column damage. 


\section{CONCLUSIONS}

A computational model of a post-tensioned concrete building tested on the E-Defence shake table was presented and subjected to three increasing intensities of the Kobe earthquake motion and compared to the measured responses. The model accurately captured the building's global drift, base moment and base shear response during the Kobe 25\% and $50 \%$ test. These tests represented a serviceability level and design level earthquake in a moderate to high seismicity region, respectively. From the accuracy of these results, it is recommended that a viscous damping ratio of $2.5 \%$ is appropriate for models of buildings that utilise self-centering concrete walls.

The model accurately captured the building response in the wall direction during the maximum credible earthquake test, Kobe $100 \%$. Furthermore, the model accurately captured the local response of the wall, including, wall uplift, neutral axis length, prestressing tendon axial force, and longitudinal energy dissipating reinforcement strain. The effects of the floor interaction on the beams in the wall direction were also accurately captured. The floor provided additional compressive and tensile forces when the beams were subjected to positive and negative rotations. The model accurately calculated the response of the floor due to vertical deformations imposed by the wall and column uplift. The accuracy with which the model calculated the measured response of the building validates the modelling approach of unbonded post-tensioned concrete walls presented by Watkins [20].

Analysis of the building's fundamental mode shapes showed that the first mode in the wall direction contained a torsional response. This elastic torsional response was captured when local variations in the measured unconfined concrete compressive strength and its effect on the wall stiffness were considered. During the Kobe $100 \%$ test, significant torsional rotations were measured, despite the building being symmetrical in plan and in elevation. On average, the model calculated approximately $50 \%$ of the measured torsional rotation for all the Kobe tests. Further research is required to understand the torsional rotations that occur during inelastic response as this model was limited in its ability to capture this complex behaviour. However, it was clear that modelling of the torsional response is important to accurately capture the response of the test building.

Furthermore, the dynamic loading of the earthquake motion increased the wall base shear and varied the column axial force compared to that calculated by the model subjected to a uni-directional pushover analysis. Dynamic loading increased the wall base shear demand by $43 \%$ and decreased the column axial force by $25 \%$ compared to the same model subjected to a pseudo-static pushover analysis. The dynamic magnification estimates in the New Zealand Concrete Structures Standard (NZS 3101:2006) are appropriate to account for the increase in wall base shear due to dynamic loading. However, the design standard does not currently explicitly prescribe a dynamic magnification factor for the column axial forces, and it is recommended that this should be considered as part of the capacity design process.

These results also show it is important to consider both the inplane and out-of-plane behaviour of the floor to accurately capture a seismic response of buildings and understand the over-strength actions that may develop and implication that this may have on the intended strength hierarchy, inelastic mechanisms, and failure modes. Additional guidance on how to assess the likely over-strength from wall-to-floor interaction to prevent undesirable failure modes is required.

\section{ACKNOWLEDGEMENTS}

The test presented was conducted by the National Research Institute for Earth Science and Disaster Prevention of Japan with financial support from the Ministry of Education, Culture, Sports, Science and Technology (MEXT) with the curated experimental data available online at NEEShub. Funding for the analytical study was partially provided by National Science Foundation in the US (CMMI Grant No: 1041650), the University of Auckland, Fulbright New Zealand and the Earthquake Commission of New Zealand. Opinions, findings, conclusions and recommendations in this paper are those of the authors, and do not necessarily represent those of the sponsors. This is QuakeCoRE publication number 153.

\section{REFERENCES}

1 Marquis F, Kim JJ, Elwood KJ and Chang SE (2017). "Understanding post-earthquake decisions on multi-storey concrete buildings in Christchurch New Zealand". Bulletin of Earthquake Engineering, 15(2): 731-758.

2 Priestley MJN, Sritharan S, Conley JR and Pampanin S (1999). "Preliminary results and conclusions from the PRESSS five-story precast concrete test building". PCI Journal, 44(6): 42-67.

3 Perez FJ, Pessiki S and Sause R (2013). "Experimental lateral load response of unbonded post-tensioned precast concrete walls". ACI Structural Journal, 110(6): 10451055.

4 Smith BJ, Kurama YC and McGinnis MJ (2011). "Design and Measured Behavior of a Hybrid Precast Concrete Wall Specimen for Seismic Regions". Journal of Structural Engineering, 137(10): 1052-1062.

5 Sritharan S, Aaleti S, Henry RS, Liu KY and Tsai KC (2015). "Precast concrete wall with end columns (PreWEC) for earthquake resistant design". Earthquake Engineering and Structural Dynamics, 44(12): 2075-2092.

6 Henry RS, Brooke NJ, Sritharan S and Ingham JM (2012). "Defining concrete compressive strain in unbonded posttensioned walls". ACI Structural Journal, 109(1): 101112.

7 Twigden KM (2016). "Dynamic Response of Unbonded Post-tensioned Concrete Walls for Seismic Resilient Structures". PhD Thesis, University of Auckland, Auckland, New Zealand.

8 Marriott D, Pampanin S, Bull DK and Palermo A (2008). "Dynamic testing of precast, post-tensioned rocking wall systems with alternative dissipating solutions". Bulletin of the New Zealand Society for Earthquake Engineering, 41(2): 90-103.

9 Holden T, Restrepo J and Mander JB (2003). "Seismic performance of precast reinforced and prestressed concrete walls". Journal of Structural Engineering, 129(3): 286296.

10 Henry RS, Sritharan S and Ingham JM (2016) "Finite element analysis of the PreWEC self-centering concrete wall system". Engineering Structures, 115: 28-41.

11 Belleri A, Schoettler MJ, Restrepo JI and Fleischman RB (2014). "Dynamic behavior of rocking and hybrid cantilever walls in a precast concrete building". $A C I$ Structural Journal, 111(3): 661-671.

12 Nagae T, Tahara K, Fukuyama K, Matsumori T, Shiohara H, Kabeyasawa T, Kono S, Nishiyama M and Nishiyama I (2012). "Seismic Performance Assessment and Improvement of Prestressed Concrete Buildings Based on E-Defence Shaking Table Test". Journal of Structural and Construction Engineering, Architectural Institute of Japan, 77(671): 75-84. 
13 Tanyeri AC (2014). "Seismic Performance and Modeling of Reinforced Concrete and Post-Tensioned Precast Concrete Shear Walls". PhD Thesis, University of California, Berkeley, California.

14 Gavridou S, Wallace JW, Nagae T, Matsumori T, Tahara K and Fukuyama K (2017). "Shake-table test of a fullscale 4-story precast concrete building. II: Analytical studies". ASCE Journal of Structural Engineering, 143(6).

15 Nagae $T$, Tahara $K$, Matsumori $T$, Shiohara $H$, Kabeyasawa T, Kono S, Nishiyama I, Wallace JW, Ghannoum W, Moehle J, Sause R, Keller W and Tuna Z (2011). "Design and Instrumentation of the 2010 EDefence Four-Story Reinforced Concrete and PostTensioned Concrete Buildings". PEER Report, (PEER2011/104).

16 Gavridou S, Wallace JW, Nagae T, Matsumori T, Tahara K and Fukuyama K (2017). "Shake-table test of a fullscale 4-story precast concrete building. I: Overview and experimental results". ASCE Journal of Structural Engineering, 143(6).

17 Standards New Zealand (2004). "NZS1770.5: 2004 Structural Design Actions". Standards New Zealand, Wellington.

18 "Four-Storey Reinforced Concrete and Post-Tensioned EDefence Building Tests". Available from: http://nees.org/warehouse/experiment/4841/project/1005.

19 SAP2000 18.1.1 (2016). Computers and Structures, Berkley, California.

20 Watkins J (2017). "Seismic Response of Buildings that Utilise Unbonded Post-Tensioned Concrete Walls". $\mathrm{PhD}$ Thesis, University of Auckland, Auckland.

21 Bentz E and Collins MP (2001). Response 2000. University of Toronto, Canada.

22 Standards New Zealand (2006). "NZS3101: 2006 Concrete Structures Standard". Standards New Zealand, Wellington.

23 Arteta CA (2015). "Seismic Response Assessment of Thin Boundary Elements of Special Concrete Shear Walls". $\mathrm{PhD}$ Thesis, University of California, Berkeley, USA.

24 Welt TS (2015). "Detailing for Compression in Reinforced Concrete Wall Boundary Elements: Experiments Simulations and Design Recommendations".
$\mathrm{PhD}$ Thesis, University of Illinois at Urbana-Champaign, Illinois, USA.

25 Mander JB, Priestley MJN and Park R (1988). "Theoretical Stress-Strain Model for Confined Concrete". Journal of Structural Engineering, 114(8): 1804-1826.

26 Moehle J (2014). "Seismic Design of Reinforced Concrete Buildings". McGraw-Hill, New York.

27 Takeda T, Sozen MA and Nielsen NN (1970). "Reinforced concrete response to simulated earthquakes". Journal of Structural Engineering, 96(12): 2257-2273.

28 Holzer S, Melosh R, Barker R and Somers A (1975). "SINGER: A Computer Code for General Analysis of Two-Dimensional Reinforced Concrete Structures". National Technical Information Service, U.S. Department of Commerce, Virginia.

29 Devalapura RK and Tadros MK (1992). "Stress-strain modeling of $270 \mathrm{ksi}$ low-relaxation prestressing strands". PCI Journal, 37(2): 100-105.

30 Darwin D and Pecknold DAW (1974). "Inelastic model for cyclic biaxial loading of reinforced concrete". University of Illinois, Illinois.

31 Vecchio FJ and Collins MP (1986). "The Modified Compressed-Field Theory for reinforced concrete elements subject to shear". ACI Journal, 83-22: 219-231.

32 He XG and Kwan AKH (2001). "Modeling dowel action of reinforcement bars for finite element analysis of concrete structures". Computers and Structures, 79: 595604.

33 Pennucci D, Calvi GM and Sullivan TJ (2009). "Displacement-based design of precast walls with additional dampers". Journal of Earthquake Engineering, 13(1): 40-65.

34 Nazari M (2016). "Seismic performance of unbonded post-tensioned precast wall systems subjected to shake table testing". PhD Thesis, Iowa State University, Iowa.

35 Nagae T, Ghannoum W, Kwon J, Tahara K, Fukuyama K, Matsumori T, Shiohara H, Kabeyasawa T, Kono S, Nishiyama I, Sause R, Wallace JW and Moehle JP (2015). "Design implications of large-scale shake-table test on four-story reinforced concrete building". ACI Structural Journal, 112(2): 135-146. 